\title{
Effects of aminoguanidine on peripheral nerve function and polyol pathway metabolites in streptozotocin-diabetic rats
}

\author{
N.E. Cameron, M. A. Cotter, K. Dines and A. Love \\ Department of Biomedical Sciences, University of Aberdeen, Scotland, UK
}

\begin{abstract}
Summary. The effect of 2 months aminoguanidine treatment on nerve conduction abnormalities was studied in streptozotocin-diabetic rats. Treatment with aminoguanidine from the induction of diabetes mellitus prevented a $22 \%$ decrease in sciatic motor nerve conduction velocity $(p<0.001)$, and a $10 \%$ deficit in sensory saphenous conduction velocity $(p<0.01)$. There was a $49 \%$ increase in resistance of sciatic nerve to hypoxic conduction failure in vitro. This was not significantly affected by aminoguanidine treatment. Sciatic nerve polyol pathway metabolites, sorbitol and fructose, were elevated 10 -fold by diabetes $(p<0.001)$. Myo-inositol levels were $18 \%$ decreased by diabetes. Aminoguanidine treatment had no significant effect on sorbitol, fructose or
\end{abstract}

myo-inositol levels. Aminoguanidine has been identified as both an inhibitor of the formation of advanced glycation end products, and an aldose reductase inhibitor. The data suggest that beneficial actions on nerve function do not depend on the latter property. They support the notion that advanced glycation end products contribute to the aetiology of early diabetic neuropathy, possibly acting via a vascular mechanism, and that aminoguanidine treatment may have therapeutic applications.

Key words: Diabetic neuropathy, aminoguanidine, polyol pathway, sorbitol, myo-inositol, advanced glycation end products, aldose reductase, streptozotocin, diabetic rat.
Several hypotheses have been proposed to account for the abnormalities in nerve function found in diabetes. One view highlights the importance of metabolic changes in neurons and Schwann cells. Thus, a hyperglycaemia-induced increase in polyol pathway flux may lead to reduced nerve myo-inositol levels and phosphoinositide turnover, compromising $\mathrm{Na}^{+}-\mathrm{K}^{+}$-ATPase activity. The consequent changes in ionic homeostasis could be responsible for functional deficits such as reduced conduction velocity, increased resistance to ischaemic conduction failure (RICF), and long-term morphological deficits including axonopathy [1]. Aldose reductase inhibitors (ARI) correct nerve dysfunction in diabetic rats [2-4], and can produce improvements in fibre regeneration in patients [5].

Low and co-workers [6] have emphasized the importance of vascular factors by demonstrating that rat sciatic nerves have reduced endoneurial blood flow and are hypoxic to an extent sufficient to cause dysfunction. Blood flow may be improved and function is normalized by vasodilator treatment [7-9]. Endoneurial hypoxia has also been measured in neuropathic patients [10]. Several reports of non-diabetic rats reared under hypoxic conditions, and of non-diabetic patients with chronic obstructive airway disease, have stressed the similarities of nerve function with those found in diabetes [11-13]. There are a number of possible causes of impaired nerve perfusion, including increased vascular reactivity $[14,15]$, deficits in vascular endothelium production of vasodilator prostacyclin [16] and nitric oxide $[17,18]$, increased synthesis of vasoconstrictor prostanoids [19], elevated blood viscosity [20] and microvascular atherogenesis dependent on advanced glycation end products (AGE) [21].

Aminoguanidine treatment prevents AGE formation [21], and has recently been shown to normalize rat sciatic nerve blood flow and improve electrophysiological and morphological indices [22, 23]. However, a further report suggests that aminoguanidine possesses substantial ARI activity [24], because there was a $75 \%$ reduction in diabetic rat lens sorbitol levels when treated for 98 days with a dose of $25 \mathrm{mg} / \mathrm{kg}$ body weight which was very similar to that used in studies of nerve function ( 25 or $50 \mathrm{mg} / \mathrm{kg}$ ) [22]. Given that ARIs correct nerve function and morphology [2-4], and may improve blood flow [25], it is not clear whether the beneficial effects of aminoguanidine depend on AGE as opposed to polyol pathway inhibition. The aim of this investigation was to measure the effect of aminoguanidine on nerve polyol pathway metabolites for correlation with any conduction velocity improvements. 
Table 1. Body weights and plasma glucose levels

\begin{tabular}{lcccc}
\hline Group & $n$ & $\begin{array}{l}\text { Start } \\
\text { weight } \\
(\mathrm{g})\end{array}$ & $\begin{array}{l}\text { Final } \\
\text { weight } \\
(\mathrm{g})\end{array}$ & $\begin{array}{l}\text { Plasma } \\
\text { glucose } \\
(\mathrm{mmol} / \mathrm{l})\end{array}$ \\
\hline $\begin{array}{l}\text { Control } \\
\text { Diabetic } \\
\begin{array}{l}\text { Aminoguanidine- } \\
\text { treated }\end{array}\end{array}$ & 12 & $484 \pm 12$ & - & $8.6 \pm 0.2$ \\
\hline
\end{tabular}

A second aim was to investigate aminoguanidine effects on RICF as this has not previously been examined.

\section{Materials and methods}

Male Sprague-Dawley rats (Aberdeen University breeding colony), 19 weeks of age at the start of the study were used. One group of nondiabetic animals acted as onset controls. Others were given streptozotocin $(40 \mathrm{mg} / \mathrm{kg}$ in $20 \mathrm{mmol} / 1$ sodium citrate buffer, $\mathrm{pH} 4.5$, i. p.). Diabetes was verified $24 \mathrm{~h}$ later by estimating hyperglycaemia and glycosuria (Visidex II and Diastix; Ames, Slough, Bucks., UK). Samples for plasma glucose measurement were taken the day of final experiments. Diabetic animals were divided into two groups, one of which was untreated for 2 months. The other group was treated with aminoguanidine (Sigma, Poole, Dorset, UK) $7.35 \mathrm{mmol} / \mathrm{l}$ given in the drinking water, which did not affect the approximately $250 \mathrm{ml}$ of water per day consumed by the diabetic rats. This treatment regimen has previously been demonstrated to prevent kidney mesangial expansion with diabetes, and results in plasma aminoguanidine levels similar to those commonly obtained using a daily i.p. injection [26].

In final experiments (1-1.5 g/kg urethane anaesthesia i.p.), conduction velocity was measured in vivo between the sciatic notch and knee for motor branches supplying tibialis anterior (peroneal division) and gastrocnemius (tibial division) muscles. Sensory conduction velocity was measured in the saphenous nerve between groin and ankle, the methods for which have previously been described in detail [27].

RICF was measured in vitro as previously described [27]. The contralateral sciatic trunk was removed and mounted on bipolar stimulating (proximal end) and recording (distal end) electrodes in a chamber at $35^{\circ} \mathrm{C}$. It contained Krebs-Ringer solution with $5.5 \mathrm{mmol} / \mathrm{glucose}$ for nerves from non-diabetic rats, and $40 \mathrm{mmol} / \mathrm{l}$ glucose for the diabetic groups. Bathing fluid was gassed with a mixture of $95 \% \mathrm{O}_{2}: 5 \% \mathrm{CO}_{2}$. Nerves were equilibrated for $30 \mathrm{~min}$, then the chamber was refilled with mineral oil pre-gassed with $100 \% \mathrm{~N}_{2}$ for $1 \mathrm{~h}$. Nerves were stimulated with just supramaximal pulses $(1 \mathrm{~Hz}$, $0.05 \mathrm{~ms}$ width, $10 \mathrm{~mA}$ ) and compound action potential amplitude was monitored at 2 -min intervals until it fell below $10 \%$ of its initial value.

Sciatic nerve sugars and polyols were determined by gas chromatography of trimethyl-silyl derivatives prepared from aqueous deproteinized extracts [28].

\section{Statistical analysis}

Data are expressed as means \pm SEM. One-way analysis of variance was performed, followed by the Bonferroni-corrected $t$-test to assign differences to individual between-group comparisons when overall significance $(p<0.05)$ was attained, using commercial software (Instat, GraphPad, San Diego, Calif., USA).

\section{Results}

Table 1 shows plasma glucose levels and body weights for all groups. Plasma glucose was elevated five-fold by diabetes, and there was a $22 \%$ weight loss. Aminoguanidine

treatment did not have a significant effect on these parameters.

Data for motor nerve conduction velocity are shown in Figure 1 for gastrocnemius and tibialis anterior sciatic motor branches. Conduction velocity was $20 \%$ and $23 \%$ reduced by untreated diabetes, respectively $(p<0.001$, both nerves). Aminoguanidine treatment prevented this reduction in conduction velocity ( $p<0.001$, both nerves), values were not significantly different from controls. Sensory saphenous conduction velocity is also shown in Figure 1 , there was a $10 \%$ decrease with diabetes $(p<0.05)$, which was prevented by treatment $(p<0.01)$.

Figure 2 shows data for RICF, and the decline in compound action potential amplitude with increasing duration of hypoxia. The decline was prolonged in nerves from untreated diabetic rats compared to controls $(p<0.05$ from 18 min onward); a similar effect was seen for aminoguanidine treatment $(p<0.01$ from 22 min onward). There were no significant differences between diabetic and aminoguanidine-treated groups at any time point. The inset graph of Figure 2 shows the times taken for an $80 \%$ decrease in compound action potential amplitude $\left(\mathrm{T}_{80}\right)$. These were $49 \%$ elevated by diabetes $(p<0.001)$, and $37 \%$ increased $(p<0.01)$ in the aminoguanidine-treated group compared to controls. There was no significant effect of aminoguanidine compared to untreated diabetes on $\mathrm{T}_{80}$.

Figure 3 shows sciatic nerve sorbitol, fructose and myoinositol levels. Sorbitol and fructose were 12-fold and 9fold elevated by diabetes respectively (both $p<0.001$ ) and this was completely unaffected by aminoguanidine treatment. Myo-inositol was $16 \%$ reduced in the diabetic group compared to controls, although this did not reach statistical significance. In the aminoguanidine-treated diabetic group, a similar $20 \%$ decrease in myo-inositol was statistically significant $(p<0.05)$ compared to nondiabetic but not to diabetic controls.
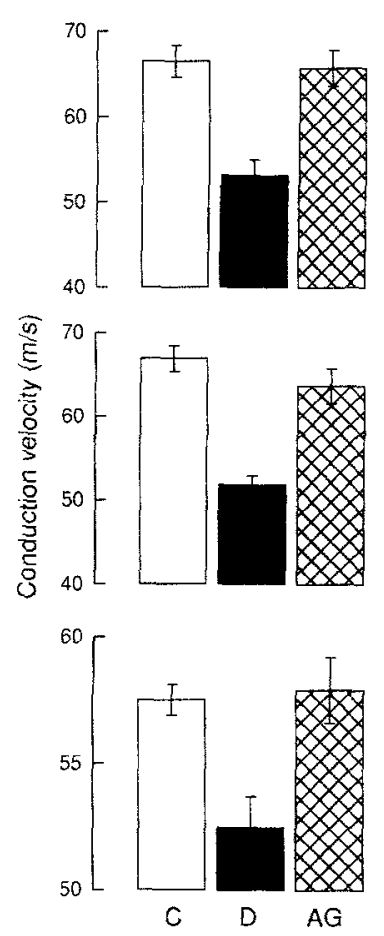

Fig. 1. Conduction velocity in sciatic motor and saphenous sensory nerves. Top panel: motor conduction to gastrocnemius muscle. Middle panel: motor conduction to tibialis anterior muscie. Lower panel: sensory saphenous conduction. C, control group $(n=12) ; \mathbf{D}$, untreated diabetic group $(n=11)$; $\mathrm{AG}$, aminoguanidine-treated diabetic group $(n=14)$. Data are group means \pm SEM 


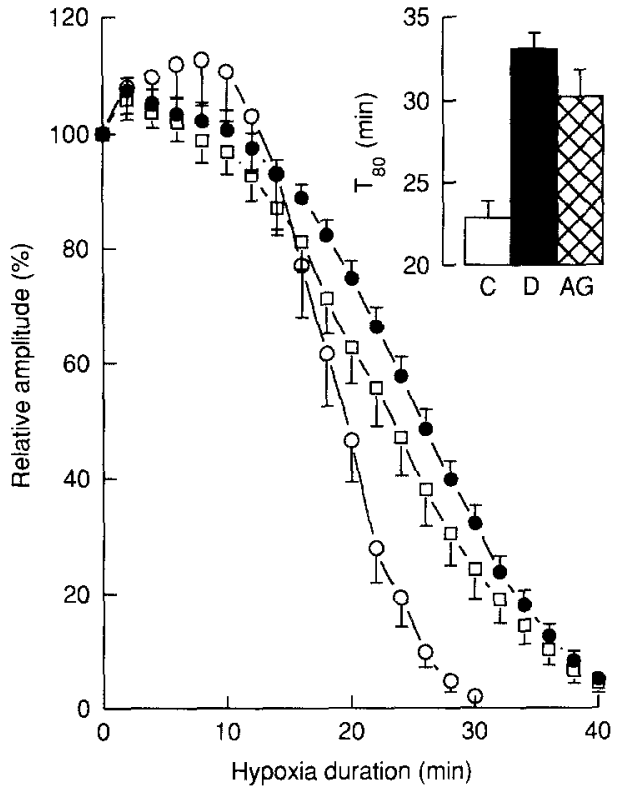

Fig. 2. Percentage change in sciatic nerve compound action potential amplitude with duration of hypoxia. Non-diabetic control (O), diabetic control $(\bullet)$, and aminoguanidine-treated diabetic ( $\square$ ) groups. The inset histogram shows the durations of hypoxia necessary for an $80 \%$ reduction in compound action potential amplitude $\left(\mathrm{T}_{80}\right)$ for non-diabetic control (C), diabetic control (D) and aminoguanidine-treated diabetic ( $\mathrm{AG}$ ) groups. Data are group means \pm SEM

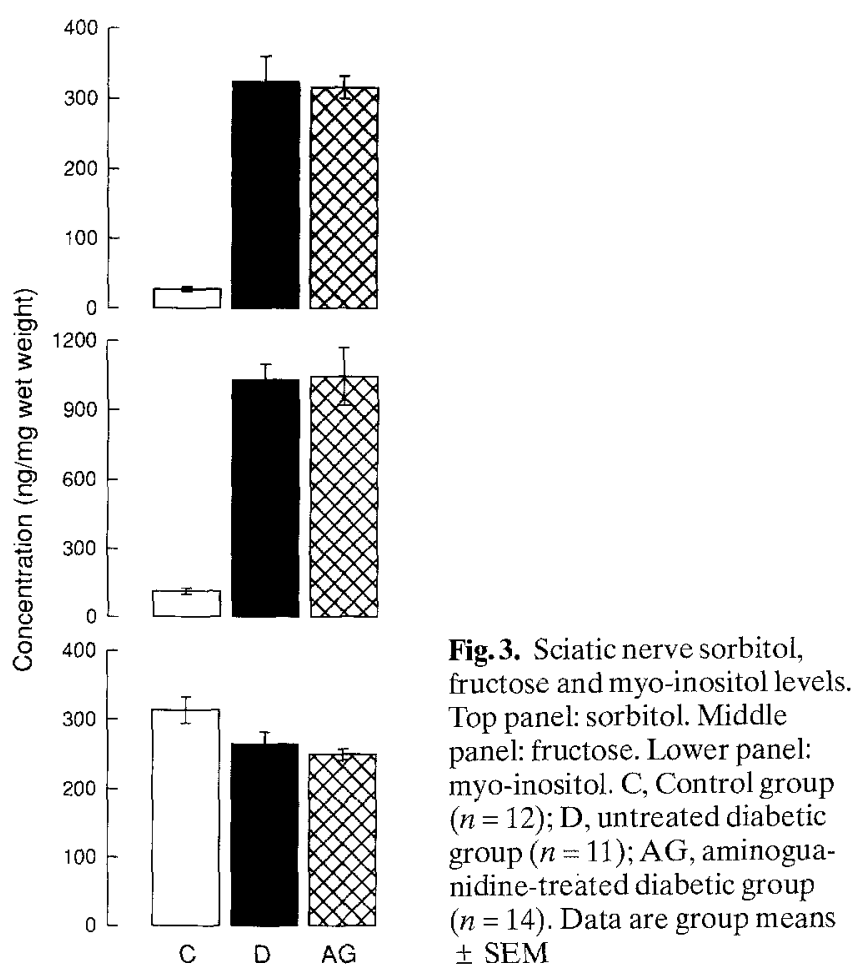

\section{Discussion}

The data demonstrate that aminoguanidine treatment prevents the development of motor and sensory conduction velocity deficits associated with diabetes. This occurred in the absence of any effect on elevated sciatic nerve polyol pathway metabolites, or on myo-inositol levels. Thus, there is no evidence from these experiments that the beneficial effects of aminoguanidine depended on an ARI action. The results also suggest that correction of a putative mechanism of nerve dysfunction, based on polyol pathway activity and a phosphoinositide-turnover-dependent reduction in $\mathrm{Na}^{+}-\mathrm{K}^{+}$-ATPase activity [1], is not relevant to the effects of aminoguanidine. This is in accord with previous findings for chronic vasodilator treatments $[8,9]$.

The lack of effect of aminoguanidine on nerve sorbitol concentration contrasts with data presented by Kumari and co-workers [24] who suggested that aminoguanidine slows the development of cataracts in diabetic rats in vivo by inhibiting polyol pathway activity. This group also provided an in vitro demonstration that aminoguanidine inhibits aldose reductase, although the $\mathrm{K}_{\mathrm{i}}$ value reported was at least two orders of magnitude greater than the dose used for the in vivo study. Thus, other interpretations of the effect of aminoguanidine on lens cataracts in vivo are possible and may be more appropriate. Aminoguanidine could have a primary effect on cataracts by preventing the formation of AGE, whereas the apparent sorbitol-lowering properties may have resulted indirectly from other mechanisms, for example by an increase in lens sorbitol permeability. Whatever the reason for the difference between this study and that of Kumari et al. [24], it is clear that aminoguanidine cannot be considered an effective ARI at the doses commonly used $[22,23,26]$ to prevent the accumulation of AGE. The potential effect of aminoguanidine on lens sorbitol concentration also requires further confirmatory studies to establish the mechanisms responsible.

The conduction velocity data support a previous report of a longer-term study [22], where aminoguanidine treatment prevented a progressive decline in sciatic-tibial nerve conduction velocity over a 24-week period. However, for caudal nerve in that study, results were more complex. Aminoguanidine caused delayed normalization of an initial defect, which developed during the first 8 weeks of diabetes of the treatment period. The reason for the difference between sciatic and caudal nerves is unclear.

The action of aminoguanidine may depend on prevention of AGE-related vascular changes. Low and co-workers [22] demonstrated that aminoguanidine prevented a decrease in sciatic resting endoneurial blood flow for over 16 weeks of diabetes. Vasodilator treatments cause similar changes in blood flow and nerve function [7-9], thus, the vascular effect of aminoguanidine should be sufficient to account for its action on conduction velocity. Aminoguanidine is not a general vasodilator, and had no effect on nerve blood flow in non-diabetic rats [22]. There are, however, several potential AGE effects on microvasculature in diabetes. In the long term, aminoguanidine prevents glomerular basement membrane thickening [21]. AGEs have been implicated in atherogenesis because they stimulate macrophage recognition and uptake, which could lead to smooth muscle proliferation in response to macrophage-derived growth factor [29]. Aminoguanidine also prevents increases in vascular permeability in retina and nerve, perhaps indicating preservation of endothelial in- 
tegrity [30]; however, diabetic effects on the blood-nerve barrier have been disputed [22]. AGEs may have a direct effect on vascular endothelium-derived relaxing factor as they quench nitric oxide in vitro [31]. Depressor responses to acetylcholine are reduced in diabetic rats and patients $[31,32]$. Endothelium-dependent relaxation to acetylcholine is impaired in aortas and several vascular beds in streptozotocin and spontaneously diabetic rats $[17,18,33$ 38], and in vascular tissue from diabetic patients [39] studied in vitro. Aminoguanidine treatment prevented the development of impaired depressor responses to acetylcholine for over 2 months in streptozotocin-diabetic rats [31]. Thus, the forestalment of abnormal endotheliumdependent nitric oxide vasodilator action on vascular smooth muscle could make a major contribution to normalizing nerve blood flow and conduction velocity.

Aminoguanidine treatment did not have a significant effect on sciatic nerve RICF. As for conduction velocity, the mechanisms underlying RICF have been disputed. The metabolic hypothesis suggests that it is a polyol-pathway related consequence of reduced $\mathrm{Na}^{+}-\mathrm{K}^{+}$-ATPase activity, hence diminished demand for ATP and oxygen [1]. The vascular hypothesis attributes RICF to an adaptation towards increased reliance on anaerobic metabolism as a result of chronic endoneurial hypoxia [40]. In isolation, the data might be taken to support the metabolic hypothesis; sorbitol and fructose, the indicators of polyol pathway activity, were not reduced by aminoguanidine treatment, and RICF was unchanged. ARIs can prevent the development of RICF [4, 41], although this has been disputed [42]. However, results from vasodilator treatment experiments also show that RICF can be prevented without any effect on nerve polyol levels $[8,9]$. We have found RICF to be a much more sensitive indicator of diabetic nerve dysfunction than conduction velocity, and correspondingly more difficult to correct. For vasodilator treatments, this may depend on relative efficacy. Over 2 months of streptozotocin-diabetes increased RICF was completely prevented by the angiotensin converting enzyme inhibitor lisinopril $\left(20 \mathrm{mg} / \mathrm{kg}\right.$ ) [9], partially prevented by the $\alpha_{1}$ adrenoceptor blocker prazosin $(5 \mathrm{mg} / \mathrm{kg})$ [8], and unaffected by the calcium channel antagonist nifedipine (40 mg/kg) (S.Robertson, N.E.Cameron, M.A.Cotter, unpublished observations); despite this, all treatments completely and indistinguishably prevented motor and sensory conduction velocity deficits. Thus, it is plausible that a vascular effect of aminoguanidine in this investigation was simply not powerful enough to prevent the development of RICF. This notion is indirectly supported by the study by Low and co-workers [22], where caudal nerve electrophysiology showed early evidence of dysfunction despite treatment. In addition, although resting sciatic blood flow was normalized by aminoguanidine in that study, an increase in conjugated dienes was nevertheless present, indicating that nerves remained under some oxidative stress. This could relate to impaired flow increases when nerves were active, which could be a stimulus for RICF development.

In conclusion, aminoguanidine prevented the development of conduction velocity deficits in diabetic rats, by a mechanism that did not depend on inhibition of polyol pathway activity. AGE-dependent effects, probably vascular related, may contribute to the aetiology of early experimental diabetic neuropathy, and this could have therapeutic implications.

Acknowledgements. This research was supported in part by a grant from the British Diabetic Association.K.D. is supported by a research studentship from Scotia Pharmaceuticals. We thank Drs. F. Carey and D. Mirrlees of Imperial Chemical Industries for organising the nerve polyol determinations.

\section{References}

1. Lattimer SA, Sima AAF, Greene DA (1989) In vitro correction of impaired $\mathrm{Na}^{+}-\mathrm{K}^{+}$-ATPase in diabetic nerve by protein kinase Cagonists. Am J Physiol 256: E264-E269

2. Cameron NE, Leonard MB, Ross IS, Whiting PH (1986) The effects of sorbinil on peripheral nerve conduction velocity, polyol concentrations and morphology in the streptozotocin-diabetic rat. Diabetologia 29: 168-174

3. Cameron NE, Cotter MA, Robertson S (1989) The effect of aldose reductase inhibition on the pattern of nerve conduction deficits in diabetic rats. Q J Exp Physiol 74:917-926

4. Price DE, Airey CM, Alani SM, Wales JK (1988) Effect of aldose reductase inhibition on nerve conduction velocity and resistance to ischemic conduction block in experimental diabetes. Diabetes 37: 969-973

5. Sima AAF, Bril V, Nathaniel V et al. (1988) Regeneration and repair of myelinated fibers in sural-nerve biopsy specimens from patients with diabetic neuropathy treated with sorbinil. N Engl J Med 319: 548-555

6. Tuck RR, Schmelzer JD, Low PA (1984) Endoneurial blood flow and oxygen tension in the sciatic nerves of rats with experimental diabetic neuropathy. Brain 107: 935-950

7. Cameron NE, Cotter MA, Low PA (1991) Nerve blood flow in early experimental diabetes in rats: relation to conduction deficits. Am J Physiol 261: E1-E8

8. Cameron NE, Cotter MA, Ferguson K, Robertson S, Radcliffe MA (1991) Effects of chronic $\alpha$-adrenergic receptor blockade on peripheral nerve conduction, hypoxic resistance, polyols, $\mathrm{Na}^{+}$$\mathrm{K}^{+}$-ATPase activity, and vascular supply in STZ-D rats. Diabetes 40: $1652-1658$

9. Cameron NE, Cotter MA, Robertson S (1992) Angiotensin converting enzyme inhibition prevents the development of muscle and nerve dysfunction and stimulates angiogenesis in streptozotocin-diabetic rats. Diabetologia 35: 12-18

10. Newrick PG, Wilson AJ, Jakubowski J, Boulton AJM, Ward JD (1986) Sural nerve oxygen tension in diabetes. Br Med J 293: 1053-1054

11. Low PA, Schmelzer JD, Ward KK, Yao JK (1986) Experimental chronic hypoxic neuropathy: relevance to diabetic neuropathy. Am J Physiol 250: E94-E99

12. Masson EA, Church SE, Woodcock AA, Hanley SP, Boulton AJM (1988) Is resistance to ischaemic conduction failure induced by hypoxia? Diabetologia 31: 762-765

13. Smith WJ, Diemel LT, Leach RM, Tomlinson DR (1991) Central hypoxaemia in rats provokes neurological defects similar to those seen in diabetes mellitus: evidence for a partial role of endoneurial hypoxia in diabetic neuropathy. Neuroscience 45 : $255-259$

14. Scarborough NL, Carrier GO (1983) Increased alpha-2 adrenoceptor mediated vascular contraction in diabetic rats. J Autonom Pharmacol 3: 177-183

15. Morff RJ (1990) Microvascular reactivity to norepinephrine at different arteriolar levels and durations of streptozocin-induced diabetes. Diabetes 39: 354-360

16. Ward KK, Low PA, Schmelzer JD, Zochodne DW (1989) Prostacyclin and noradrenaline in peripheral nerve of chronic experimental diabetes in rats. Brain 112: 197-208 
17. Hattori Y, Kawasaki H, Kazuhiro A, Kanno M (1991) Superoxide dismutase recovers altered endothelium-dependent relaxation in diabetic rat aorta. Am J Physiol 261: H1086-H1094

18. Cameron NE, Cotter MA (1992) Modulation of endothelium dependent relaxation by polyol pathway activity in aorta from chronic streptozotocin-diabetic rats. Eur J Clin Invest 22: A53 (Abstract)

19. Tesfamariam B, Jakubowski JA, Cohen RA (1989) Contraction of diabetic rabbit aorta caused by endothelium-derived $\mathrm{PGH}_{2}-$ TxA 2 . Am J Physiol 257: H1327-H1333

20. Barnes AJ, Locke P, Scudder PR, Dormandy JL, Dormandy JA, Slack J (1977) Is hyperviscosity a treatable component of diabetic microcirculatory disease? Lancet II: 789-791

21. Brownlee M, Vlassara H, Kooney A, Ulrich P, Cerami A (1986) Aminoguanidine prevents diabetes-induced arterial wall protein cross-linking. Science 232: 1629-1632

22. Kihara M, Schmelzer JD, Poduslo JF, Curran GL, Nickander KK, Low PA (1991) Aminoguanidine effects on nerve blood flow, vascular permeability, electrophysiology and oxygen free radicals. Proc Natl Acad Sci USA 88: 6107-6111

23. Yagihashi S, Kamijo M, Baba M, Yagihashi N, Nagai K (1992) Effect of aminoguanidine on functional and structural abnormalities in peripheral nerve of STZ-induced diabetic rats. Diabetes 41: 47-52

24. Kumari K, Umar S, Bansal V, Sahib MK (1991) Inhibition of diabetes-associated complications by nucleophilic compounds. Diabetes 40: 1079-1084

25. Yasuda H, Sonobe M, Yamashita Met al. (1989) Effect of prostaglandin $E_{1}$ analogue TFC 612 on diabetic neuropathy in streptozocin-induced diabetic rats: comparison with aldose reductase inhibitor ONO 2235. Diabetes 38: 832-838

26. Soulis-Liparota T, Cooper M, Papazoglou D, Clarke B, Jerums G (1991) Retardation by aminoguanidine of development of albuminuria, mesangial expansion, and tissue fluorescence in streptozocin-induced diabetic rat. Diabetes 40: 1328-1334

27. Cameron NE, Cotter MA, Robertson S (1991) Effects of essential fatty acid dietary supplementation on peripheral nerve and skeletal muscle function and capillarization in streptozocin diabetic rats. Diabetes 40: 532-539

28. Stribling D, Mirrless DJ, Harrison HE, Earl DCN (1985) Properties of ICI 128, 436, a novel aldose reductase inhibitor and its effects on diabetic complications in the rat. Metabolism 34: 336-344

29. Brownlee M, Cerami A, Vlassara H (1988) Advanced glycosylation end products in tissue and the biochemical basis of diabetic complications. N Engl J Med 318: 1315-1321

30. Corbett JA, Tilton RG, Chang K et al. (1992) Aminoguanidine, a novel inhibitor of nitric oxide formation, prevents diabetic vascular dysfunction. Diabetes 41: 552-556

31. Bucala R, Tracey K, Cerami A (1991) Advanced glycosylation products quench nitric oxide and mediate defective endothe- lium-dependent vasodilation in experimental diabetes. J Clin Invest $87: 432-438$

32. McVeigh G, Brennan G, Johnston GD, Hayes R (1991) Impaired endothelium dependent and independent responses in non-insulin dependent diabetes mellitus. Diabetologia 34 [Suppl 2]: A16 (Abstract)

33. Durante W, Sen AK, Sunahara FA (1988) Impairment of endothelium-dependent relaxation in aortae from spontaneously diabetic rats. Br J Pharmacol 94: 463-468

34. Mahan WG (1989) Impairment of endothelium-dependent dilation of cerebral arterioles during diabetes mellitus. Am J Physiol 256: H621-H625

35. Takiguchi Y, Satoh N, Hashimoto H, Nakashima M (1989) Reversal effect of thyroxine on altered vascular reactivity in diabetic rats. J Cardiovasc Pharmacol 13:520-524

36. Lash JM, Bohlen HG (1991) Structural and functional origins of suppressed acetylcholine vasodilation in diabetic rat intestinal arterioles. Circ Res 69: 1259-1268

37. Hill MA, Larkins RG (1989) Altered microvascular reactivity in streptozotocin-induced diabetes in rats. Am J Physiol 257: H1438-H1445

38. Gross R, Hillaire-Buys D, Bertrand G, Ribes G, LoubatieresMariani M-M (1989) Diabetes and impaired response of glucagon cells and vascular bed to adenosine in rat pancreas. Diabetes 38: 1291-1295

39. Saenz de Tejada I, Goldstein I, Azadzoi K, Krane RJ, Cohen RA (1989) Impaired neurogenic and endothelium-mediated relaxation of penile smooth muscle from diabetic men with impotence. N Engl J Med 320: 1025-1030

40. Low PA, Tuck RR, Takeuchi M (1987) Nerve microenvironment in diabetic neuropathy. In: Dyck PJ, Thomas PK, Asbury AK, Winegrad AI, Porte D (eds) Diabetic neuropathy. Saunders, Philadelphia, pp 266-278

41. Cameron NE, Cotter MA (1991) Partial dissociation of the effects of aldose reductase inhibition on sciatic nerve biochemistry, conduction velocity and hypoxic resistance in streptozotocindiabetic rats. Diabetic Med 8 [Suppl 1]: P93 (Abstract)

42. Carrington AL, Ettlinger CB, Calcutt NA, Tomlinson DR (1991) Aldose reductase inhibition with imirestat - effects on impulse conduction and insulin-stimulation of $\mathrm{Na}^{+} / \mathrm{K}^{+}$-adenosine triphosphatase activity in sciatic nerves of streptozotocin-diabetic rats. Diabetologia 34: 397-401

Received: 27 April 1992

and in revised form: 15 June 1992

Dr.N.E.Cameron

Department of Biomedical Sciences

University of Aberdeen

Marischal College

Aberdeen AB9 1 AS

Scotland UK 